\title{
ETHICAL ISSUES, BREAKDOWN DURING COVID-19 PANDEMIC ERA IN UPPER AND LOWER EGYPT
}

\author{
Haidy M. Fakher ${ }^{1}$, *Eman S. Shaltout ${ }^{2}$ \\ Department of Forensic Medicine and Clinical Toxicology, Faculty of Medicine-Benha \\ University-Egypt ${ }^{1}$, Department of Forensic Medicine and Clinical Toxicology, Faculty of \\ Medicine-Assiut University-Egypt ${ }^{2}$ \\ *Corresponding author: Eman Salah Shaltout, emansalahshaltout@yahoo.com.
}

\begin{abstract}
Introduction: Outbreaks of infectious disease are also marked by sociocultural unrest, and a general atmosphere of fear and mistrust. On 30 January 2020, a COVID-19 (Coronavirus disease 2019) epidemic was declared an international public health emergency, this outbreak provoked a negative association, social stigma and a discriminatory behavior against people of certain ethnic foundations as well as anybody seen to have been in contact with the infection. Aim of the study: The goal of this study is to concentrate on the relationships between stigma evoked during the COVID-19 pandemic, breaking the privacy and confidentiality of infected individuals and job affection, social harm, seeking health assistance and also promoting awareness of these issues among Egyptians. Subjects and Methods: A comparative cross-sectional study questionnaire on a random sample of 500 respondents (250 for each) conducted at Benha city and Assiut city, Egypt. Results: Respondents to the questionnaire revealed that $60.0 \%$ of Upper Egypt preferred to home quarantine while (53.2\%) of Lower Egypt preferred hospital quarantine. Most respondents from both Upper and Lower Egypt agreed to do COVID-19 PCR (Polymerase chain reaction) test. In addition, respondents in Upper and Lower Egypt declined to publish their names because participants in Upper Egypt related their refuse due to affection on their social lives while participants in Lower Egypt refused to publish their names because of a violation of their privacy. Conclusions: COVID-19 infection pandemic has a negative effect on the ethical issues as confidentiality breakdown of patients, emergence of stigma, economic and social implications.
\end{abstract}

Keywords: Covid-19 outbreak, Ethical issues, patient's privacy, Hospital quarantine, Home isolation.

\section{INTRODUCTION}

Emerging viruses represent a threat and outbreak to global public health; they have caused many deaths, morbidities, and cost billions of dollars (Fan et al., 2019). Like other diseases and their associated burdens, COVID-19 is likely to cause suffering and misery as much or greater than other infectious diseases around the planet. COVID-19 is assumed to have arisen in early December 2019 from a wet market in Wuhan, China, with highly efficient human to-human transmission, it spread rapidly around China, and has now traversed the globe. The World Health Organization (WHO) has declared a global public health emergency, and recently defined COVID-19 as a global pandemic (Gostin et al., 2020).

Outbreak Episodes be a worldview for ethical issues postured by epidemic crises, through the joining of such subjects as: separation and isolation, privacy and confidentiality and the elucidation of ethical standards across different ethno cultural settings. The ongoing pandemic of COVID-19 has brought to light ethical issues driving patient care as well as research (Calain et al., 2009 and Guo et al., 2020).

Social media Press outlets, including television and magazines, have played a significant role in educating, influencing the public's view of health issues, and 
Spreading public health knowledge and skills (Shim and You., 2015). The number of people using social media, such as Facebook or Twitter, has risen in recent years, and the use of social media as a source of health information can influence people's awareness or actions related to health problems, including perceptions of risks and preventive behavior, because social media can breach one's privacy and can be used to breach privacy, the confidentiality of others and racism in times of epidemic and civil unrest (Barman-Adhikari et al., 2016 \& Young et al., 2011).

In Egypt, there are 37.9 million users in the digital society and two thirds of them have influential Facebook pages, with a total of 22 million male users, while 12 million female users (MCIT., 2018).

Healthcare and scientific research ethics revolve around concerns related to fundamental human rights and the provision of healthcare, ensuring protection and benefits for the populations, preventing damage of any kind while maintaining privacy and confidentiality and ensuring social justice in these efforts (Piot et al., 2014).

The aim of this study is to focus on the relationships between stigmas aroused during COVID-19 pandemic, break privacy \& confidentiality of infected patients and job affection, social harm, seeking medical advice and also to promote awareness of Egyptian people about these issues, in a group of people from two large cities in Egypt with a COVID-19 ward.

\section{SUBJECTS AND METHODS}

This was a comparative crosssectional study conducted at Benha city [Al-Qalyubia Governorate] and Assiut city [Assiut Governorate], Egypt. Data was collected over a period of 2 months (from $1^{\text {st }}$ March 2020 till $30^{\text {th }}$ April 2020). Random sample of 500 respondents (250 for each) from different strata of society who were accepted to participate in the study.
- Inclusion criteria: they were eighteen years old and older at the time, medical and paramedical persons, and relatives to COVID-19 patients.

- Exclusion criteria: patients infected with COVID-19 at the time of the study and patients with psychological disorders affect their decision.

\section{Questionnaire analysis:}

Researchers designed a questionnaire of quite a series of questions to learn about the effect of COVID-19 pandemic infection on ethical issues. The first part contains questions describing demographic data that includes age, gender, education, jobs and social status. The second part includes questions that describe public attitude to COVID-19 infection; when they feel symptoms of COVID-19 infection, what do you do if they feel symptoms, if they agree to be swabbed for laboratory investigation and if they prefer quarantine at home or in hospital. The last section outlined the impact of stigmatization in social media on people response, if they interested in knowing names of affected people from social media and why? And if they agree others to know their names if they been infected and why?

\section{Ethical approval}

This study had the approval from the board of ethical review of Assiut Medical School. The participants received an informed written consent (in Arabic language). It included their personal data and the study information as title, goals, methodology, expected benefits and risks and data confidentiality.

\section{Data analysis}

The demographic data and Questionnaire results include both males and females, social, educational, and marital status from both Upper and Lower Egypt were analysed.

Data had been imported into Mathematica from Excel (version 10.1; Wolfram) using the latter software, figures were generated, and descriptive statistics were calculated. 


\section{RESULTS}

The results of the demographic distribution of the respondents illustrated a wide range of ages in this study from 18 to 66 years old. The study showed $(58.4 \%$, 48.0\%) male in Upper and Lower Egypt respectively. A large majority of the respondents were also married. Most respondents held a college-level education and their job were employees (Table 1).

Table (1): Frequency and percentage distribution of the studied groups according to their demographic data $(n=500)$.

\begin{tabular}{|c|c|c|c|c|}
\hline & \multicolumn{2}{|c|}{ Upper Egypt } & \multicolumn{2}{|c|}{ Lower Egypt } \\
\hline Age(mean) & \multicolumn{2}{|c|}{41.008} & \multicolumn{2}{|c|}{36.752} \\
\hline Male & 146 & $58.4 \%$ & 120 & $48 \%$ \\
\hline Female & 104 & $41.6 \%$ & 130 & $52 \%$ \\
\hline \multicolumn{5}{|c|}{ Social status } \\
\hline Single & 48 & $19.20 \%$ & 64 & $25.60 \%$ \\
\hline Married & 184 & $73.60 \%$ & 156 & $62.40 \%$ \\
\hline Divorced & 8 & $3.2 \%$ & 14 & $5.60 \%$ \\
\hline Widow & 10 & $4 \%$ & 16 & $6.40 \%$ \\
\hline \multicolumn{5}{|c|}{ Level of education } \\
\hline Postgraduate & 110 & $44 \%$ & 33 & $13.20 \%$ \\
\hline University & 84 & $33.60 \%$ & 131 & $52.40 \%$ \\
\hline Secondary & 48 & $19.20 \%$ & 78 & $31.20 \%$ \\
\hline Illiterate & 8 & $3.2 \%$ & 8 & $3.20 \%$ \\
\hline \multicolumn{5}{|c|}{ Job } \\
\hline Not employed & 56 & $22.40 \%$ & 68 & $27.20 \%$ \\
\hline Free work & 54 & $21.60 \%$ & 61 & $24.40 \%$ \\
\hline Employee & 130 & $52 \%$ & 108 & $43.20 \%$ \\
\hline - $\quad$ Craftsman & 10 & $4 \%$ & 13 & $5.20 \%$ \\
\hline
\end{tabular}

For research question [When feel symptoms of COVID-19 infection, what you do?] the results revealed $(60.0 \%)$ of Upper Egypt respondents preferred to home quarantine but (53.2\%) of Lower Egypt respondents preferred to go to hospital. Most respondents in both Upper and Lower Egypt agreed to do COVID-19 test. Approximately $56.80 \%$ of Upper Egypt and $79.20 \%$ of Lower Egypt respondents favored to quarantine themselves at hospital if the COVID-19 test were positive (Table 2).

Table (2): Percentage of the studied groups regarding their action towards COVID-19 infection $(n=500)$.

\begin{tabular}{|c|c|c|c|c|}
\hline & \multicolumn{2}{c|}{ Upper Egypt } & \multicolumn{2}{c|}{ Lower Egypt } \\
\hline \multicolumn{4}{|c|}{ When feel symptoms of COVID-19 infection: } \\
\hline $\begin{array}{c}\text { Go to a private } \\
\text { doctor. }\end{array}$ & 12 & $4.80 \%$ & 36 & $14.40 \%$ \\
\hline Go to the hospital. & 88 & $35.20 \%$ & 133 & $53.20 \%$ \\
\hline Home quarantine. & 150 & $60 \%$ & 81 & $32.40 \%$ \\
\hline \multicolumn{7}{|c|}{ Agree to do COVID-19 test: } \\
\hline Yes & 202 & $80.80 \%$ & 236 & $94.40 \%$ \\
\hline No & 48 & $19.20 \%$ & 14 & $5.60 \%$ \\
\hline
\end{tabular}




\begin{tabular}{|l|c|c|c|c|}
\hline \multicolumn{4}{|c|}{ If the COVID-19 were positive; What do you prefer? } \\
\hline $\begin{array}{c}\text { Quarantine } \\
\text { yourself at home. }\end{array}$ & 108 & $43.20 \%$ & 52 & $20.80 \%$ \\
\hline $\begin{array}{c}\text { Go to } \\
\text { quarantine. hospital }\end{array}$ & 142 & $56.80 \%$ & 198 & $79.20 \%$ \\
\hline
\end{tabular}

For research question [Do they agree to publish their names if they infected on social media pages?]; Results showed that (76.80\% \& $74.40 \%)$ Upper and Lower Egypt respondents respectively declined publishing their names as about $(53.13 \%)$ of Upper Egypt respondents referred their refuse to the affection on their social life while $(69.35 \%)$ of Lower Egypt respondents refusing to violation of their privacy.

Thirty two percentage of Upper Egypt respondents preferred to know the names of the infected persons due to avoid contact with the infected person as $(62.50 \%)$ was illustrated while $(68.00 \%)$ did not agree to know the names of the infected persons due to maintain patient privacy $(55.29 \%)$. A large majority of the respondents of Lower Egypt $(67.60 \%)$ preferred to know the names of the infected persons due to avoid contact with the infected person as showed $(75.73 \%)$. while $(32.40 \%)$ did not agree to know the names of the infected persons due to maintain patient privacy $(74.07 \%)$. Authors declared that respondents from both Upper and Lower Egypt who did not agree to know the names of the infected persons because it affects social life and their work had free work (Table 3).

Table (3): Effect of the social media news regarding COVID-19 infection on studied groups $(n=500)$.

\begin{tabular}{|c|c|c|c|c|}
\hline & \multicolumn{2}{|c|}{ Upper Egypt } & \multicolumn{2}{|c|}{ Lower Egypt } \\
\hline \multicolumn{5}{|c|}{ Do they agree to publish their names if they infected on social media pages? } \\
\hline Yes & 58 & $23.20 \%$ & 64 & $25.60 \%$ \\
\hline No & 192 & $76.80 \%$ & 186 & $\mathbf{7 4 . 4 0 \%}$ \\
\hline \multicolumn{5}{|l|}{ IF No, Why? } \\
\hline -Violation of privacy. & 24 & $12.50 \%$ & 129 & $69.35 \%$ \\
\hline - Affects career. & 66 & $34.47 \%$ & 19 & $10.21 \%$ \\
\hline - Affects social life. & 102 & $53.13 \%$ & 38 & $20.43 \%$ \\
\hline \multicolumn{5}{|c|}{$\begin{array}{l}\text { If they are not COVID-19 infected, would they prefer to know the names of the } \\
\text { infected? }\end{array}$} \\
\hline Yes & 80 & $32.00 \%$ & 169 & $67.60 \%$ \\
\hline \multicolumn{5}{|l|}{ Why? } \\
\hline $\begin{array}{l}\text { To avoid contact with } \\
\text { the infected person. }\end{array}$ & 50 & $62.50 \%$ & 128 & $75.73 \%$ \\
\hline $\begin{array}{l}\text { To find out if I were } \\
\text { in contact with the } \\
\text { infected person. }\end{array}$ & 26 & $32.50 \%$ & 35 & $20.71 \%$ \\
\hline Without reason. & 4 & $5 \%$ & 6 & $3.55 \%$ \\
\hline NO & 170 & $68.00 \%$ & 81 & $32.40 \%$ \\
\hline \multicolumn{5}{|l|}{ Why? } \\
\hline $\begin{array}{l}\text { To maintain patient } \\
\text { privacy. }\end{array}$ & 94 & $55.29 \%$ & 60 & $74.07 \%$ \\
\hline Don't care. & 64 & $37.64 \%$ & 21 & $25.92 \%$ \\
\hline Others. & 12 & $7.05 \%$ & $\mathbf{0}$ & $\mathbf{0 0}$ \\
\hline
\end{tabular}


Seventy five percentage of females participants from Upper Egypt discussed refusal of publishing their names on the social media due of violation of their privacy, while most of male participants from both Upper and Lower Egypt want to go to hospital if they felt Covid-19 infection symptoms, while males from both Upper and Lower Egypt stated that publishing their names will affect their work fields as shown in Figure 1.

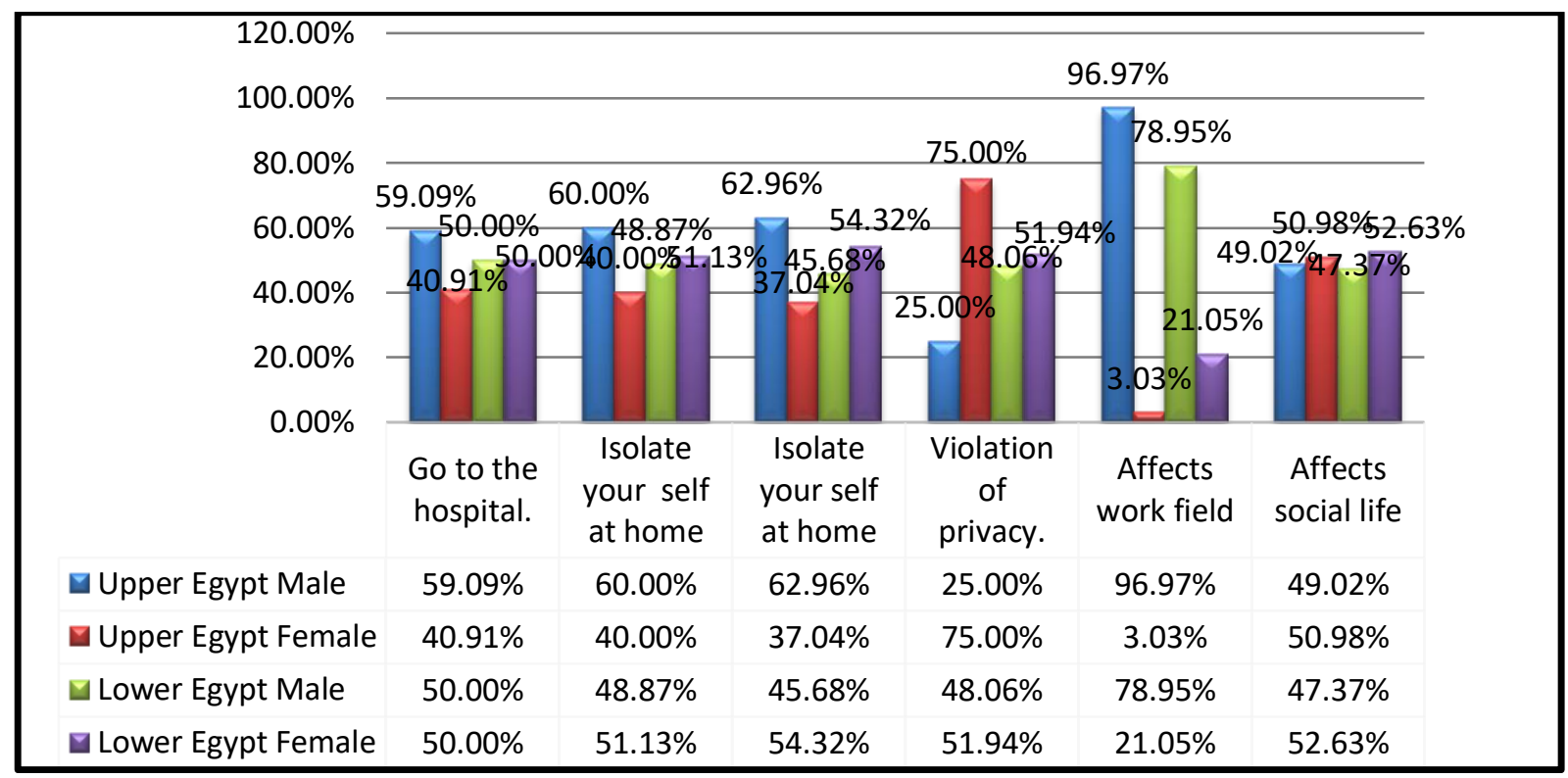

Figure (1): Correlation between sex of respondents and their response if they get infection with covid-19 infection and the cause of their refusal of publishing their names on social media.

In this questionnaire authors observed that most respondents that refuse to do the necessary laboratory investigations for COVID-19 infection from both Upper and Lower Egypt were having master and bachelor's degree, respectively. Also, more than half of participants from Upper and Lower Egypt who have master and bachelor's degree preferred home quarantine (Fig. 2\&3). 


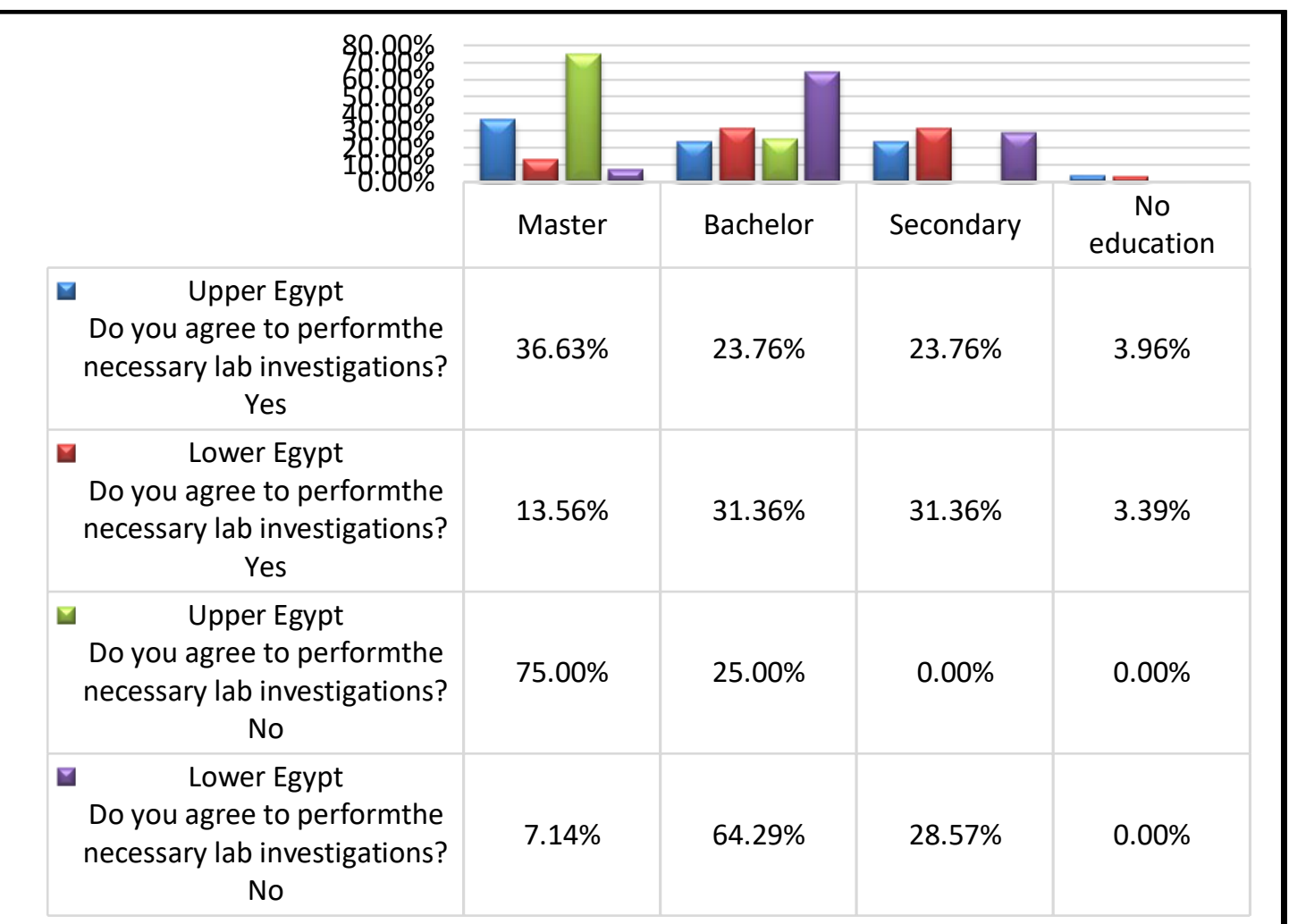

Figure (2): Correlation between education level of respondents and if they agree to perform laboratory investigation.

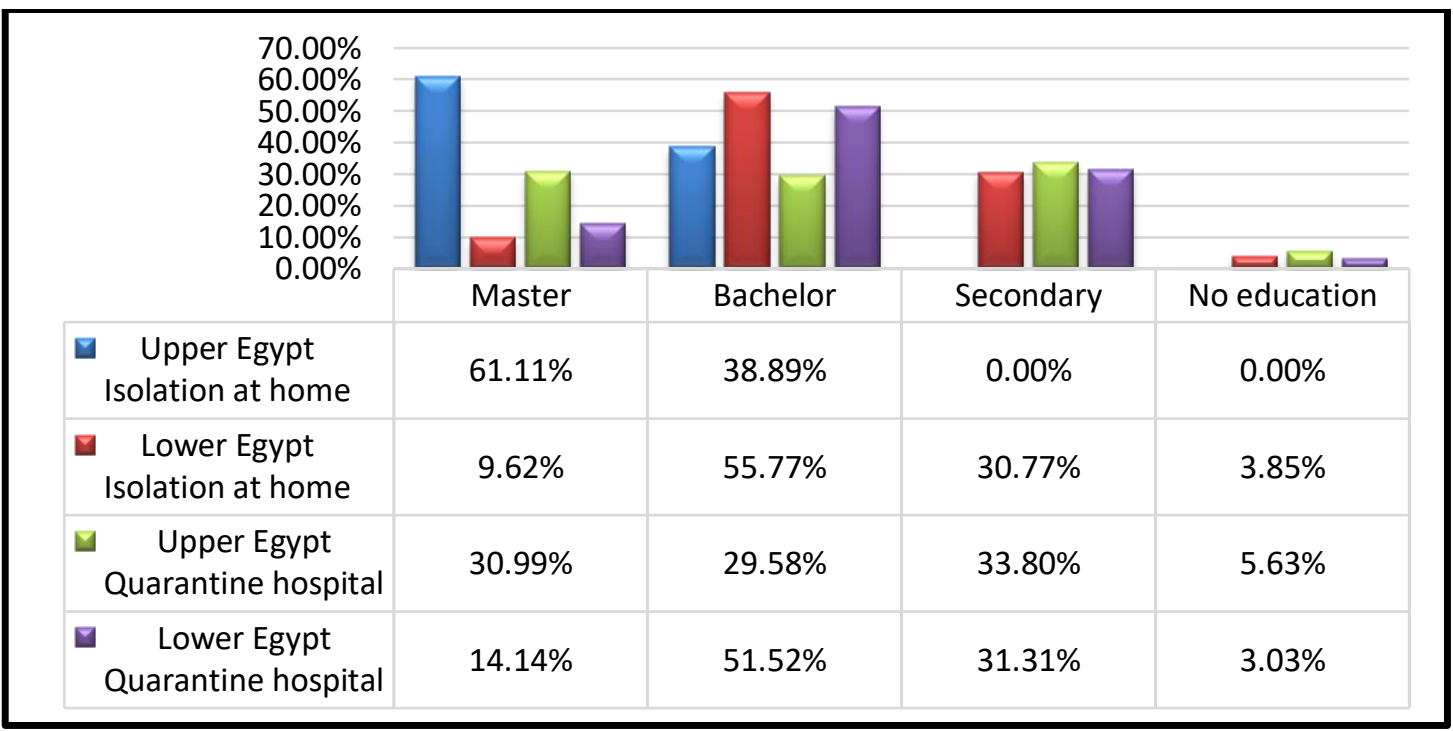

Figure (3): Correlation between education level of respondents and what they do When feel symptoms of COVID-19 infection.

\section{DISCUSSION}

Pandemics and acute emergencies present serious problems to the medical, legal and organization. These include global governance, priority setting, patient triage, scarce resource allocation and restriction of individual freedom in the public health interest (Simonds and Sokol., 2009).

Health-related stigma is stigma related to living with a particular illness or health condition. A negative association happens when individuals adversely relate an irresistible infection, such as COVID-19, with a particular people. In the case of 
COVID-19, there are a growing number of reports of public social stigma toward people from regions affected by the outbreak. Unfortunately, this means that some people are classed, stereotyped, isolated and/or suffered loss of autonomy and prejudice due to a possible negative relation to the disease. In times of crisis the media's significance is increased. Government and responsible entities regard media as an integral component of crisis management (Reynolds and Seeger., 2005), and the public relies on the media to make sense of messy or confusing situations (Tai and Sun. 2007\& Zhang et al. 2015).

A lot of people who survived the infection are now struggling with a lot of social stigma about the disease, such stigma can be experienced in all spheres of life; however, at a time when people are at their most vulnerable, this stigma negatively affects people seeking health services, such as making some people wait longer or hinders access to rapid medical care, early treatment and better results, stigma also affects health sector well-being as health care employees may also be working under stigmatized conditions. They can hide their own state of health from colleagues and are unwilling to access and participate in treatment (Ramaci et al., 2020).

It is the primary responsibility to protect the safety of the patient, and to make it clear as to its limits. The disclosure must be made only with the consent of the patient or the consent of the legally approved individual; it can also be made only if required by law without the consent of the patient (APA., 2010).

The present study shows a majority of respondents in Upper Egypt favored home quarantine while respondents in Lower Egypt favored hospitalization. Both the respondents from Upper Egypt and Lower Egypt favored quarantining themselves in hospital if the COVID-19 test was positive. Those findings were consistent with Austrian et al., (2020) who showed that when the participants were asked what they would do if they had COVID-19 symptoms. The most likely response was "going to a doctor" (71\%). Just $42 \%$ said they'd call the toll-free hotline from the government and just $19 \%$ said they'd spend more at home. Griffin., (2020) has also been shown that about 97.3 percent of citizens with a serious underlying health condition should remain at home and away from others. The guidance from the World Health Organization is to stay home and call a health care provider if symptomatic, especially given the limited testing capabilities in certain settings (WHO, 2020).

The present study showed that respondents in Upper and Lower Egypt declined to publish their names as respondents in Upper Egypt referred their refusal to the affection in their social life while denying respondents in Lower Egypt for violation of their privacy; these were in line with Austrian et al., (2020), since many study participants, mostly men and older adults, expressed concerns about income loss and food shortages. That was one of the main reasons given why quarantine or 14-day self-isolation was not feasible, Lee et al., (2016) further illustrated that in the outbreak of a new infectious disease, negative attitudes may be exacerbated by both the unfamiliar origin and the fatal outcome and the breakdown of daily routines and shame. Prior research has also shown that people often feel more victimized during crises than is required by the current level of risk (Coombs and Slovic.,1979).

Results showed that Upper and Lower Egypt respondents declined publishing their names, referred their refuse to the affection on their social life or violation of their privacy. The concept that medical knowledge of a patient including his / her identity remains unrevealed is generally balanced with circumstances where a voluntary violation of confidentiality is required to protect the community from danger (Odia and George., 2008). 
The public release of names is immoral, not in the best interest of everyone and also impedes attempts to conceal. This is because it is unlikely that people will seek protection or collaborate with surveillance efforts if they think their personal information would soon become available to the public (Maduka and Odia., 2015).

Dangerous infectious diseases pose specific ethical problems, as those suffering from them are "both victims and vectors of disease". But if someone is a victim or a vector of a disease, we should note that they are still an individual and as such deserve to have their private information protected, especially if disclosure is unlikely to gain and may well damage the interests of the public, no matter how interested they are in knowing it (Hunter., 2014).

This research is confined by its small number of participants and use of a questionnaire for convenience. A larger, more representative sample size would have some generality. Because of the small sample, these results can only be applied to those participants who were able to take part in this form of research.

\section{CONCLUSIONS}

COVID-19 pandemic has a major impact on the ethical issues as breakdown patient's privacy and stigma creation which had a negative impact on both social and economic life in Upper and Lower Egypt regions. Also as s consequence, stigma is an obstacle to treat people seeking proper medical services and for the maintenance of a good quality of life, therefore; ethical principles and guidelines will need to evolve in the coming years based on the experiences gathered from the current pandemic.

\section{REFRENCES}

ASA (American Psychological Association) (2010): Ethical principles of psychologists and code of conduct. Am Psychol 65.

Austrian K. Pinchoff J. Tidwell JB. White C. Abuya T. Kangwana B, et al. (2020): COVID-19 related knowledge, attitudes, practices and needs of households in informal settlements in Nairobi, Kenya. Bull World Health Organ. E-pub: 6.

Barman-Adhikari A. Rice E. Bender K. LengnickHall R. Yoshioka-Maxwell A. Rhoades H. (2016): Social networking technology use and engagement in HIV-related risk and protective behaviors among homeless youth. J Health Commun 21 (7): 809 817.

Calain P. Fiore N. Poncin M. (2009): Research ethics and international epidemicresponse: the case of Ebola and Marburg hemorrhagic fevers. Public Health Ethics 2:7-29.

Coombs T. Slovic P. (1979): Newspaper coverage of causes of death. $J$ Mass Commun Q56: 837-849.

Fan Y. Zhao K. Shi ZL. Zhou P. (2019): Bat coronaviruses in China. Viruses, 11: 210.

Gostin OL. Friedman AE. Wette (2020); Responding to COVID-19: How to Navigate a Public Health Emergency Legally and Ethical. Hastings Center Rep 50: 1-5.

Griffin AR. (2020): Relationship between ethical orientation and consensus with public health messaging during a pandemic. This study is a preprint and has not been peer-reviewed.

Guo YR. Cao QD. Hong ZS. Tan YY. Chen SD. Jin HJ. Tan KS. Wang D. Yan Y. (2020): The origin, transmission and clinical therapies on coronavirus disease 2019 (COVID-19) outbreak - An update on the status. Milit Med Res 7:11.

Hunter D. (2014): Ebola in the US: privacy, public interest and the ethics of media reporting. J Med Ethics Blog.

Lee D. Kim J. Kang H. (2016): The emotional distress and fear of contagion related to Middle East Respiratory Syndrome (MERS) on general public in Korea. Korean $J$ Psychol: Gen 35: 355-383. 
Maduka O. Odia O. (2015): Ethical challenges of containing Ebola: the Nigerian experience. $J$ Med Ethics 41(11):917-919.

MCIT. (The Egyptian Ministry of Communications and Information Technology) (2018): The Ministry of Communications and Information Technology, ICT indicators in brief.

Odia OJ. George A. (2008): Law and Ethics of Medical Practice in Nigeria. $1^{\text {st }}$ ed. Port Harcourt: Qualihealth Communications.

Piot P. Muyembe JJ. Edmunds WJ. (2014): Ebola in West Africa: from disease outbreak to humanitarian crisis. Lancet Infect Dis 14:10341035.

Ramaci T. Barattucci $M$. Ledda C. Rapisarda V. (2020): Social Stigma during COVID-19 and its impact on HCWs, outcomes Sustainability,12; (3834): 1-13.

Reynolds B. Seeger MW. (2005): Crisis and emergency risk communication as an integrative model. $J$ Health Commun 10: 43-55.

Shim M. You M. (2015): Cognitive and affective risk perceptions toward food safety: Mediating the relation between news use and food consumption intention. Asian J Commun 25: 48-64.

Simonds AK. Sokol DK. (2009): Lives on the line? Ethics and practicalities of duty of care in pandemics and disasters. Eur Respir J 34(2):303-309.

Tai Z. Sun T. (2007): Media dependencies in a changing media environment: The case of the 2003 SARS epidemic in China. New Media Soc 9: 987-1009.

WHO (World Health Organization) (2020): Coronavirus Disease Situation Reports Geneva, Switzlerland: World Health Organization; 2020 [cited March 25, 2020]. Available from: https://www.who.int/emergencies/dise ases/novel-coronavirus-2019/situationreports.

Young SD. Rice E. (2011): Online social networking technologies, HIV knowledge, and sexual risk and testing behaviors among homeless youth. AIDS and Behav 15 (2): 253-260.

Zhang L, Kong Y, Chang H (2015) Media use and health behavior in H1N1 flu crisis: The mediating role of perceived knowledge and fear. Atlant J Commun 23: 67-80. 


\section{دراسة إنتهاك بعض القضايا الاخلاقية خلال جائحة كورونا في مصر

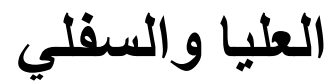 \\ هايدي محمد فخر، إيمان صلاح الدين شلتوت
}

أعلنت منظمة الصحة العالمية في 30 يناير 2020 عن تفني وباء كورونا، وأثنار تفثي هذا الوباء ارتباطيًا سلبيًا

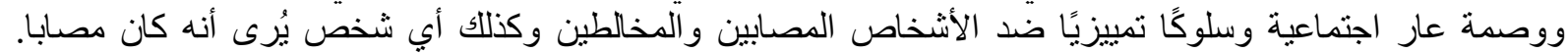

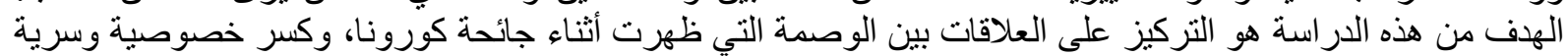

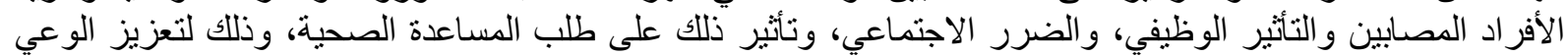

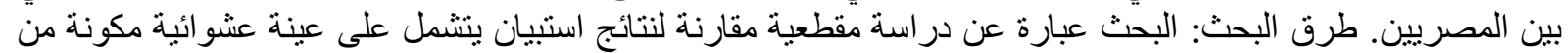

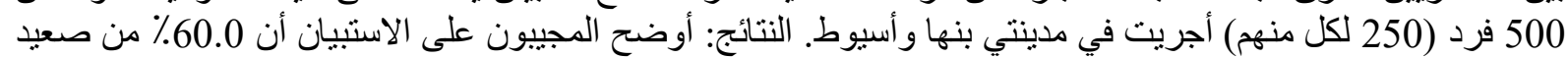

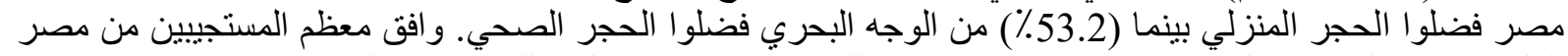

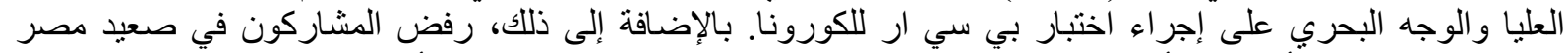

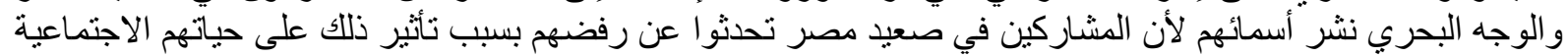

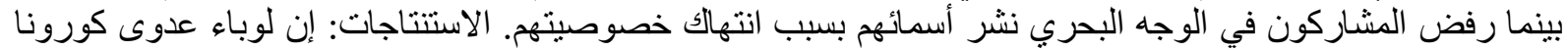

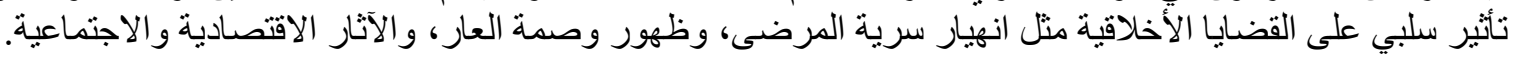

